\title{
ADJUNCTIVE EFFECT OF VIT D TO LOCAL CORTISONE IN TREATING ORAL LICHEN PLANUS LESIONS IN MENOPAUSAL AND POST- MENOPAUSAL EGYPTIAN WOMEN
}

\author{
Malak Yousef Shoukheba*
}

\begin{abstract}
This study was conducted to evaluate the effect of Vitamin D (Vit D) supplementation to topical corticosteroids in the treatment of oral lichen planus (OLP) among postmenopausal women. Thirty post-menopausal women, their ages ranging between 45-65 years, diagnosed with any form of Oral lichen planus and presenting with serum 25 Hydroxyvitamin D levels below 30ng/ ml were randomly allocated into one of two groups (15 patients each) and treated as follows: The control group I, received topical cortisone alone; The experimental group II, who were treated with topical cortisone supplemented with Vit D every week for one month. Serum level of TNF- $\alpha$, clinical and pain scores were carried out at the time of the initial visit and at 2, 4, and 6 weeks.
\end{abstract}

Results showed improvement in clinical score. Both treatment modalities resulted in a statistically significant decrease in pain score, and TNF- $\alpha(P<0.001)$ compared to the baseline values. There was no statistically significant difference between the two groups $(P>0.05)$ at any evaluation period for the pain score, while TNF- $\alpha$ showed statistically significant differences at 4 weeks only in favor to group II $(P<0.05)$.

Conclusion: Within the limitation of this study, it can be concluded that Vit D supplementation to conventional therapy can help in treating OLP among post-menopausal women. Attention must be given to educate the women in this critical age to pay attention to Vit D deficiency to avoid such serious diseases.

KEY WORDS: Oral Lichen planus, postmenopausal women, Vit D

\section{INTRODUCTION}

Oral lichen planus (OLP) is a chronic mucocutaneous disease with an immunological etiology ${ }^{1}$. OLP predominantly affects patients in the 4th to 6th decade of their life and have a predilection for females. ${ }^{2}$
The etiology of LP is not completely understood but a T-cell mediated autoimmune mechanism is proposed. The activated $\mathrm{T}$ cells, particularly $\mathrm{CD} 8+\mathrm{T}$ cells, directed against basal keratinocytes causing damage of the basal cell of the epithelium and chronic inflammation have been suggested ${ }^{3}$.

\footnotetext{
* Oral medicine and Periodontology, Faculty of Dentistry Tanta University
} 
Furthermore in OLP lesions, langerhans cells and MHC class II expression is up regulated, followed by keratinocyte apoptosis triggered by $\mathrm{CD} 8+$ cytotoxic T-cells ${ }^{4,5}$.

Reticular type of Oral lichen planus is most commonly affecting the buccal mucosa with no symptoms. Burning sensation and pain are mostly associated with erosive or atrophic lichen planus. ${ }^{6}$

Menopause is usually between the 45th and 55 th year of life and refers to the years of hormonal change before and after the last spontaneous menstruation. A variety of symptoms and conditions, such as night sweats and shot flashes, is predictably a characteristic of this period. This may resulted in severe impairment of quality of life and depressive moods ${ }^{7}$.

The incidence of OLP is higher in peri and post -menopausal women than in general population and increases significantly with increase in the severity of depression ${ }^{8,9}$.

To our knowledge, Vit D plays an important role in women's health, menopause represents an important transition in Vit D requirements because of the dependence of the Vit $\mathrm{D}$ receptor (VDR) on estrogen. ${ }^{10-}$ Additionally, the increased requirement for calcium across the menopausal transition is a reflection of the loss of VDRs hence, an increased requirement for Vit $\mathrm{D}^{11}$. Moreover, multiple polymorphisms of the VDR protein have been recognized, which may also increase the requirement for Vit $\mathrm{D}^{12}$.

Furthermore, aging affects multiple steps in the metabolism of Vit D, beginning with the reduced efficiency in the vitamin's synthesis by aging skin upon exposure to UVB radiation ${ }^{13}$. Consequently, the older adult requires approximately 3 times the duration of exposure as the younger adult to generate the same amount of Vit D

So, the postmenopausal syndromes of osteoporosis, muscle weakness, falls, osteoporotic fractures, depressed mood, cognitive impairment and dementia may be a consequence of the Vit D deficiency state ${ }^{14}$.

Majority of the researches have reported about immune regulation of Vit D and its insufficiency among patients with autoimmune disorders ${ }^{15,16}$. Hence, the aim of the present study was to investigate Vit D supplementation as an adjunctive treatment of oral lichen planus among post-menopausal women who are suffering from Vit D deficiency.

\section{MATERIAL AND METHODS}

Serum Vit D level estimation was advised for every patient. Usually, Vit D deficiency is defined as $25(\mathrm{OH}) \mathrm{D}<20 \mathrm{ng} / \mathrm{mL}$, insufficiency as $20-29 \mathrm{ng} /$ $\mathrm{mL}$, and sufficiency as $\geq 30 \mathrm{ng} / \mathrm{mL}$.

- Randomized controlled clinical trial was conducted on 30 females Post-menopausal patients there ages ranged between $45-65$ years diagnosed with any form of Oral lichen planus and presenting with Serum 25 Hydroxy vitamin D levels below 30ng/ $\mathrm{ml}$ were selected from the Out-patient clinic of Department of Oral Medicine \& Diagnosis, Faculty of Dentistry, Tanta University to be included in this study.

- This study was conducted in the period from October 2017 to November 2018. All participants received full written and verbal information about the study and signed the informed consent form. The study complied with the Helsinki Declaration of 1964, as revised in 2004.

\section{Exclusion criteria}

- All those who reported of consuming tobacco in any form, any dermatological disease, endocrine dysfunction, co-morbid or malignancy, patients on hormone replacement therapy, or reported to have consumed pain killers (NSAID's) during last four weeks, Patients with oral lesion due to fixed drug reaction or amalgam restoration. Patients who were already on Vit D 
supplementation or on systemic steroids were excluded from this study.

- Randomization with the flip coin method was used to assign study participants into any of the two groups.

\section{Group I (15 patients)}

The control group received topical corticosteroids therapy alone - triamcinolone acetonide (Kenalog in orabase: Bristol-Myers Squibb, Spain) applied topically four times a day, that is, following each meal and at bedtime for 1 month.

\section{Group II (15 patients)}

The experimental group included 15 patients who were treated with both topical corticosteroids: triamcinolone acetonide (Kenalog in orabase: Bristol-Myers Squibb) applied topically four times a day, that is, following each meal and at bedtime for 1 month, supplemented with Vit D (Devarol-s-200000 I.U) (Memphis for pharmaceuticals \&Chemical Industries 8 Sawah st-El-Amirya-Cairo-Egypt) every week for a period of one month.

The symptoms and signs of the patients in both arms were clinically assessed at baseline, after 2, 4 and 8 weeks of the initial visit by a single investigator.

The pain was assessed using Visual Analogue scale (VAS) ranging from 0-10 where 1-4 was considered as mild pain, 5-7 as moderate pain and a score above 8 was recognized as pain of severe intensity.

-The clinical data were scored according to criteria used by Thongprasom et al ${ }^{17}$.

- Score 5=white striae with erosive area more than $1 \mathrm{~cm}$

- Score 4=white striae with erosive area less than $1 \mathrm{~cm}$.

- Score 3=white striae with atrophic area more than $1 \mathrm{~cm}$
- Score $2=$ white striae with atrophic area less than $1 \mathrm{~cm}$

- Score $1=$ mild white striae, no erythematous area

- Score $0=$ no lesion, normal mucosa.

\section{Serum TNF- $\alpha$ Evaluation}

Five-milliliter venous blood was withdrawn from both patients' groups before and after treatment. Centrifugation of all blood samples was performed after 30 minutes from their collection. They were then stored in $-20^{\circ} \mathrm{C}$ temperature until laboratory analysis carried on. Quantitation of TNF- $\alpha$ in serum was done by using TNF- $\alpha$ ELISA Kit provided by AviBion, Helsinki FINLAND.

\section{Statistical analysis}

All the results were tabulated and statistically analyzed using SPSS software (version 10@; SPSS Inc., Chicago, Illinois, USA). Data were presented as means and SDs. The two study groups were compared using independent samples $t$-test. Moreover, within each group, the paired sample $t$-test was used to determine significant changes between time points for parametric data. The significance level was set at $P$ value less than 0.05

\section{RESULTS}

The LP patients groups included 30 women their ages ranged from 45 to 65 years, with a mean \pm SD of $45.60 \pm 10.82$ years. All the patients were age and sex matched $(P<0.05)$.

TABLE (1) Mean \pm SD of age, among the study group

\begin{tabular}{|c|c|c|c|}
\hline & $\begin{array}{c}\text { Group I (N=15) } \\
\text { (topical cortisone } \\
\text { only) }\end{array}$ & $\begin{array}{c}\text { Group II (N=15) } \\
\text { (topical cortisone } \\
\text { +vit D) }\end{array}$ & t test (P) \\
\hline Age & $51.31 \pm 4.33$ & $50.64 \pm 3.51$ & 0.432 \\
\hline
\end{tabular}

Level of significance at $P<0.05^{*} P$ value was determined using the independent sample $t$ test. $P$ value was determined using the fisher's exact test. 
There were no differences between the experimental groups in lesion size, pain sensation, and severity of lesions at baseline.

TABLE (2) Mean scores of visual analogue scales (VAS) among the study groups at baseline, 2,4 , and 6 weeks after treatment

\begin{tabular}{|c|c|c|c|c|c|}
\hline $\begin{array}{r}\text { VAS } \\
\text { Score } \\
\text { time }\end{array}$ & $\begin{array}{r}\text { Group I }(\mathrm{N}=15) \\
\text { (topical } \\
\text { cortisone only) }\end{array}$ & $\begin{array}{c}\text { Group II (N=15) } \\
\text { (topical cortisone } \\
\text { +vit } \mathrm{D})\end{array}$ & \multirow{2}{*}{$\mathrm{P}$} \\
\cline { 2 - 5 } & $\mathrm{X} \pm \mathrm{SD}$ & $\mathrm{t}$ test & $\mathrm{X} \pm \mathrm{SD}$ & $\mathrm{t}$ test & \\
\hline Baseline & $5.6 \pm 0.73$ & & $5.73 \pm 0.70$ & & $\begin{array}{c}0.185 \\
\mathrm{P}=0.67\end{array}$ \\
\hline 2 weeks & $2.8 \pm 0.67$ & 10.7 & $2.13 \pm 0.91$ & 11.7 & $\begin{array}{c}1.05 \\
\mathrm{P}=0.31\end{array}$ \\
\hline 4weeks & $1.73 \pm 0.70$ & 15.1 & $1.33 \pm 0.70$ & 16.1 & $\begin{array}{r}1.98 \\
\mathrm{P}=0.17\end{array}$ \\
\hline 6weeks & $2.8 \pm 0.63$ & 11.9 & $1.86 \pm 0.51$ & 15.1 & $\begin{array}{r}0.63 \\
\mathrm{P}=0.43\end{array}$ \\
\hline & \multicolumn{2}{|c|}{$\mathrm{P}=000^{* * * *}$} & \multicolumn{2}{|c|}{$\mathrm{P}=000^{* * * *}$} & \\
\hline
\end{tabular}

***P Significant change over time within groups compared with baseline values.

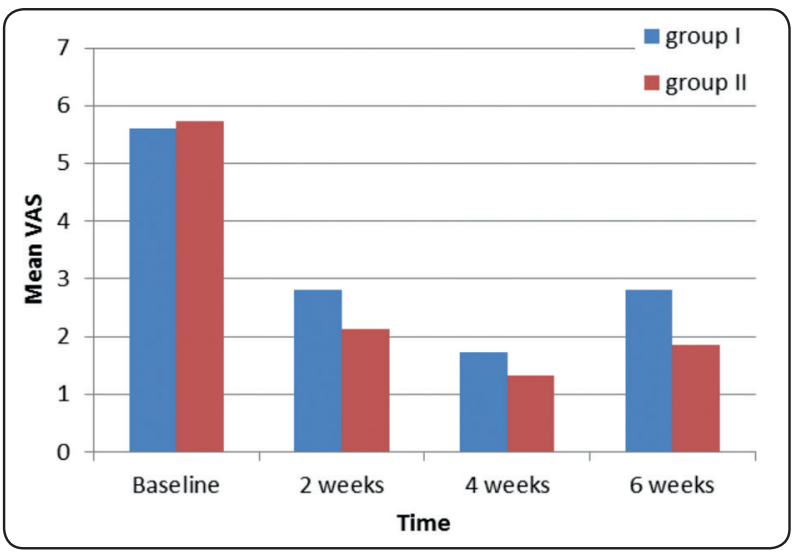

Fig. (1): Shows the effect of treatment modalities on VAS score at the different evaluation periods

Table 2 showed that both treatment modalities led to a dramatic decrease in pain and burning sensation among OLP patients and the change was statistically significant $(P<0.001)$ as compared with baseline values. However, the difference between the two groups was not statistically significant $(P>0.05)$ at any evaluation period (fig 1).
TABLE (3) Mean scores of TNF- $\alpha$ among the study groups at baseline, 2, 4, and 6 weeks after treatment

\begin{tabular}{|c|c|c|c|c|c|}
\hline \multirow[t]{2}{*}{ time } & \multicolumn{2}{|c|}{$\begin{array}{l}\text { Group I }(\mathrm{N}=15) \\
\text { (topical cortisone } \\
\text { only) }\end{array}$} & \multicolumn{2}{|c|}{$\begin{array}{l}\text { Group II }(\mathrm{N}=15) \\
\text { (topical cortisone } \\
+ \text { vit } \mathrm{D})\end{array}$} & \\
\hline & $\mathrm{X} \pm \mathrm{SD}$ & $\mathrm{t}$ test & $\mathrm{X} \pm \mathrm{SD}$ & $t$ test & \\
\hline Baseline & $32.7 \pm 3.10$ & & $33.2 \pm 3.71$ & & $\begin{array}{c}0.441 \\
\mathrm{P}=0.512\end{array}$ \\
\hline 2 weeks & $23.9 \pm 3.20$ & 8.7 & $23.6 \pm 3.12$ & 11.7 & $\begin{array}{c}0.117 \\
\mathrm{P}=0.735\end{array}$ \\
\hline 4weeks & $20.4 \pm 2.90$ & 14.1 & $17.1 \pm 1.91$ & 16.1 & $\begin{array}{c}5.549 \\
\mathrm{P}=0.026^{*}\end{array}$ \\
\hline 6weeks & $22.6 \pm 5.50$ & 3.5 & $19.5 \pm 1.64$ & 15.1 & $\begin{array}{c}2.324 \\
P=0.139\end{array}$ \\
\hline & $\begin{array}{r}\mathrm{P}=000^{\text {**** }}, \mathrm{P} \\
\mathrm{P}=006\end{array}$ & $00^{* * * *,}$ & $\mathrm{P}=000$ & & \\
\hline
\end{tabular}

***P Significant change over time within groups compared with baseline values.

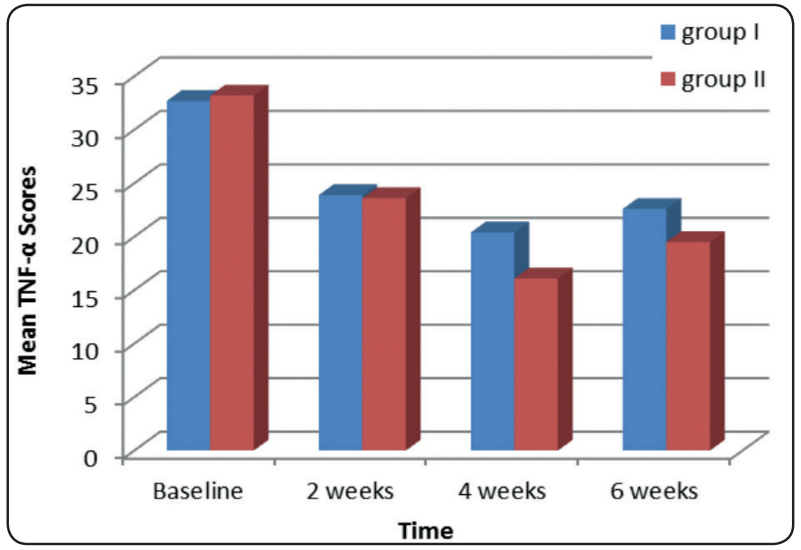

Fig. (2): Shows the effect of the treatment modalities on the mean TNF- $\alpha$ score at different evaluation periods

Table 3: showed the effect of both treatment modalities on the level of TNF- $\alpha$, both treatment modalities resulting in a statistically significant reduction in mean TNF- $\alpha$ level as compared to the baseline values $(P<0.001)$. However the differences between the two groups were not statistically significant $(P>0.05)$ at all evaluation periods except at 4 weeks whereas there a statistically significant difference in favor to the combined therapy of local cortisone and Vit $\mathrm{D}$ group II $(P<0.05)$.fig $(2)$ 
TABLE (4) Sign scores before and after treatment in each group

\begin{tabular}{|l|l|l|l|l|l|l|l|c|}
\hline \multirow{2}{*}{ Score } & \multicolumn{5}{|c|}{ Group 1 } & \multicolumn{4}{c|}{ Group 2 } \\
\cline { 2 - 9 } & Baseline & 2 weeks & 4 weeks & 6 weeks & Baseline & 2 weeks & 4 weeks & 6 weeks \\
\hline Score 5 & $66.6 \%(10)$ & & & & $73.3 \%(11)$ & & & \\
\hline Score 4 & $33.3 \%(5)$ & $80 \%(12)$ & & & $26.6 \%(4)$ & & & \\
\hline Score 3 & & $20 \%(3)$ & & $53 \%(8)$ & & $66.6 \%(10)$ & & \\
\hline Score 2 & & & $80 \%(12)$ & $46 \%(7)$ & & $33.3 \%(5)$ & $80 \%(12)$ & $46.6 \%(7)$ \\
\hline Score 1 & & & $20 \%(3)$ & & & & & $53.3 \%(8)$ \\
\hline Score 0 & & & & & & & $20 \%(3)$ & \\
\hline
\end{tabular}

Table 4 showed that an improvement in the clinical appearance of lesion was seen for patients who were treated by standard therapy plus vitamin D (group II) (fig. 4). In group I, 66.6\% (10 patients) of the patients were under score 5 and $33.3 \%$ (5 patients) were under score 4 at baseline. At 2 weeks, $80 \%$ (12 patients were under score 4 and $20 \%$ (3patients) under score 3. At 4 weeks, 20\% (3 patients) under score 1 was observed and $80 \%(12)$ of them were under score 2 . At 6 weeks, recurrence or relapse of the lesion in $53 \%$ (8) of the patients under score 3 and $46 \%$ under score 2 (fig.3).



Fig. (3) Patient treated with topical cortisone only (GI). (a) The buccal mucosa showing erythematous and ulcerative lesions; (b) clinical response after 6 weeks; (c) palatal mucosal lesion of LP at baseline (d) clinical response after 6 weeks. 


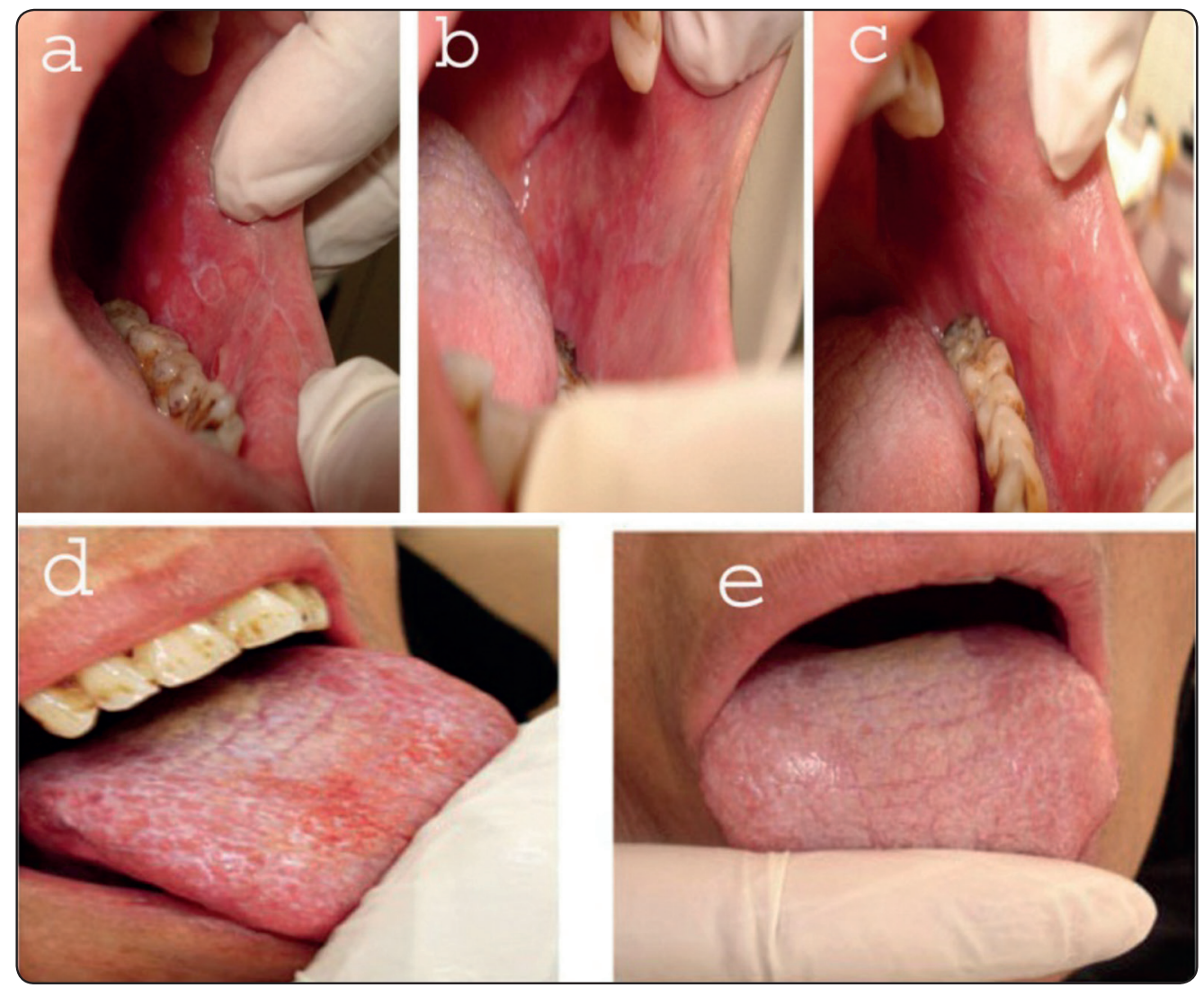

Fig. (4) Patient treated with topical cortisone+ Vt D Supplement (group II): (a) the buccal mucosa showed erythematous and ulcerative change; (b) clinical response after 2 weeks of treatment; (c) clinical responses after 6 weeks; (d) tongue lesion of LP at baseline (e) tongue lesion at 6 weeks

On the other hand, in group II, 73.4\% (11) were under score 5 and $26.6 \%$ under score 4 at baseline. At 2 weeks, initial healing 66.6\% (10) under score 3, partial healing was observed in $33.4 \%$ (5) with score 2. After 1 month, complete remission was observed in $20 \%$ (3) of the patients and partial healing in $80 \%$ (12) of the patients were under score 2. While at 6 weeks $46.6 \%$ (7) of the patients were still under score 2 and $53.4 \%(8)$ of the patients were under score 1 (fig.4). Hence, Vit D can exert little an adjunctive effect to local cortisone in treating oral lichen planus in menopausal and post-menopausal women.

\section{DISCUSSION}

The incidence of oral lichen planus most commonly reported among the female population of peri and postmenopausal age bracket ${ }^{18}$. OLP in peri and post- menopausal women can be mediated by the declined level of estrogen and Progesterone directly or indirectly through causing depression that can trigger LP. ${ }^{19}$

Estrogen increases the activity of the enzyme responsible for activating Vit $\mathrm{D}$, so declining estrogen levels during the menopausal transition could lead to symptoms of Vit D deficiency ${ }^{20}$. Hence, there is a strong correlation between vit $\mathrm{D}$ deficiency and the incidence of lichen planus.

Moreover, some biological data suggesting that there is a link between Vit D and menopauserelated symptoms. Since Vit D can protect against experimental serotonin depletion in rats and a menopausal decline in serotonin, that has effects on thermoregulation that may be a contributor to hot flashes ${ }^{21,22}$ 
Many studies indicated that the highest prevalence of autoimmune disorders is associated with Vit D deficiency such as rheumatoid arthritis, systemic lupus erythematosus, type I diabetes mellitus, multiple sclerosis, inflammatory diseases of the intestine, Hashimoto and Graves diseases of the thyroid, and autoimmune gastritis ${ }^{23,24}$.

Moreover, the deficiency of Vit D leads to dysregulation of T-cell proliferation, thus Vit D can play a great role in the initiation or severity of OLP, this was also reported in a study done by Zhao et al. indicates that lipopolysaccharide is responsible for VDR down-regulation in oral keratinocytes, which is associated with OLP development ${ }^{25}$. Therefore, it is necessary to pay attention to Vit D levels in community members, especially in those with LP.

Moreover, Varma et $\mathrm{al}^{26}$ reported in his study a case with the presence of lichen planus and Vit D deficiency, and the condition improved after vit D treatment.

Hence this study was conducted to show the adjunctive effect of Vit D to local cortisone in treating oral lichen planus lesions in menopausal and post- menopausal Egyptian women.

The results of the current study showed a significant reduction in the mean VAS score after both of treatment modalities at all evaluation periods as compared to their mean baseline values $(\mathrm{P}<0.001)$. However, more reduction was observed in relation to group II (combined treatment) but there are no significant differences between both treatments at any evaluation periods.

Results of the present study showed also an improvement in the clinical appearance of lesion was seen for patients who were treated by standard therapy plus vitamin D (group II) as after 1 month, complete remission was observed in $20 \%$ (3) of the patients and partial healing in $80 \%$ (12) of the patients under score 2, and at 6 weeks $46.6 \%$ (7) of the patients at 6 weeks still under score 2 and $53.4 \%(8)$ of the patients) under score 1 .
These findings were consistent with the study done by Gupta et al., ${ }^{27}$ who showed marked improvement and long-term remission of OLP lesion after the restoration of normal Vit D level. This confirms its role in the pathogenesis of OLP like other autoimmune diseases. This indicated the possible role of Vit D in the healing of OLP. Additionally, Razi et $\mathrm{al}^{18}$., showed that Vit D supplementation along with conventional therapy facilitates in curing OLP among peri-menopausal women.

Results of the present study were also showed that TNF- $\alpha$ was statistically significantly decreased after both treatment modalities as compared to their baseline values with more reduction with group II (local cortisone and vit D), however, the differences between the two groups were not statistically significant $(P>0.05)$ at all evaluation periods except at 4 weeks whereas there a statistically significant difference in favor to the combined therapy of group II. This is indicated that Vit D has an adjunctive anti-inflammatory effect to local cortisone.

This can be explained by the in-vitro study done by Alroy et $\mathrm{al}^{28}$., who showed suppression of $\mathrm{T}$ lymphocyte proliferation by the active metabolite of Vit D, and thus decreases interleukin 2 (IL-2), gamma interferon (IFN- $\gamma$ ), and granulocyte-macrophage-colony-stimulating factor mRNA levels.

And this also supported by $\mathrm{Yu}$ and Cantorna ${ }^{29}$ who observed that, Vit D not only promotes the proliferation of Natural Killer $\mathrm{T}$ cells but also increases IL- 4 and IFN- $\gamma$ production of Natural Killer T cells. ${ }^{29}$ Hence, the effects of Vit D on multiple immune cells indicate its role in immunemediated disorders.

From the results of the present study it was shown that low vitamin D level plays an important role in the pathogenesis of OLP. Within the limitation of this study the outcomes can support the potential role of vitamin D in the treatment of OLP. 


\section{RECOMMENDATIONS}

Long term study with a large sample size is needed to confirm the role of Vit D in the treatment of OLP in patients with Vit D deficiency like postmenopausal women and patients who do not expose to the sun light. Finally, we must pay attention to educate the women in this critical age to pay attention to Vit D deficiency to avoid such serious diseases.

\section{Financial support and sponsorship}

Nil.

\section{Conflict of interest}

The authors declare no conflict of interest

\section{REFERENCES}

1- Crincoli V, Di Bisceglie MB, Scivetti M, Lucchese A, Tecco S, Festa F. Oral lichen planus: Update on etiopathogenesis, diagnosis and treatment. Immunopharmacol Immunotoxicol. 2011;33:11-20

2- Alam F, Hamburger J. Oral mucosal lichen planus in children. Int J Paediatr Dent. 2001;11:209-14.

3- Oliveira Alves MG, Almeida JD, Balducci I, Guimarães Cabral LA. Oral lichen planus: a retrospective study of 110 Brazilian patients. BMC Res Notes 2010; 3:157-160.

4- Scully C, Beyli M, Ferreiro MC, Ficarra G, Gill Y, Griffiths $\mathrm{M}$, et al. Update on oral lichen planus: etiopathogenesis and management. Crit Rev Oral Biol Med 1998; 9:86-122.

5- Sugerman PB, Savage NW, Walsh LJ, Zhao ZZ, Zhou XJ, Khan A, et al. The pathogenesis of oral lichen planus. Crit Rev Oral Biol Med 2002; 13:350-365.

6- Scully C., Porter S. ABC of oral health: Swellings and red, white, and pigmented lesions. Br. Med. J. 2000;321:225.

7- Zeleke BM, Bell RJ, Billah B, Davis SR . Vasomotor symptoms are associated wth depressive symptoms in community-dwelling older women. Menopause; 2017, 24:1365-1371.

8- Mohamadi Hasel K, Besharat MA, Abdolhoseini A, Alaei Nasab S, Niknam S. Relationships of personality factors to perceived stress, depression, and oral Lichen Planus severity. Int J Behav Med. 2013 ;20:286-92.
9- Kossard S, Lee M-S, Wilkinson B. Postmenopausal frontal fibrosing alopecia: a frontal variant of lichen planopilaris. Journal of the American Academy of Dermatology. 1997; 36:59-66

10- Duque G, El Abdaimi K, Macoritto M, Miller MM, Kremer R. Estrogens (E2) regulate expression and response of 1, 25-dihydroxyvitamin D3 receptors in bone cells: changes with aging and hormone deprivation. Biochem Biophys Res Commun. 2002 ;299:446-54

11- Munir J, Birge S. Vitamin D deficiency in pre and postmenopausal women. Meno Manag. 2008;17:10-21.

12- .Zhai M.X, Liang L, Yang R, Dong YH. Association of vitamin $\mathrm{D}$ receptor gene polymorphism with osteoporosis in patients with diabetes mellitus. 2005 Chin J of Clini Rehab. 9:177-179

13- MacLaughlin J, Holick MF. Aging decreases the capacity of human skin to produce vitamin D3. J Clin Invest 1985; 76: 1536-1538.

14- Khan QJ, Reddy PS, Kimler BF, Sharma P, Baxa S, O'Dea A, et al. Effect of vitamin D supplementation on serum 25-hydroxy vitamin D levels, joint pain, and fatigue in women starting adjuvant letrozole treatment for breast cancer. Breast Cancer Res Treat. 2010;119:111-8.

15- Deluca HF, Cantorna MT. Vitamin D: its role and uses in immunology. FASEB J. 2001;15:2579-2585

16- Cutolo M, Pizzorni C, Sulli A. Vitamin D endocrine system involvement in autoimmune rheumatic diseases. Autoimmun Rev. 2011;11:84-87.

17- Thongprasom K, Dhanuthai K. Steriods in the treatment of lichen planus: a review. J Oral Sci. 2008; 50:377-385

18- Razi I, Mohiuddin S, Abdul Karim A, Iqbal A. Vitamin D As An Adjuvant Therapy To Cure Oral Lichen Planus In Peri-Menopausalwomen. Pakistan Oral \& Dental J. 2019; 38:399-403.

19- Mohan RS, Gupta A, Kamarthi N, Malik S, Goel S, and Gupta S. Incidence of Oral Lichen Planus in Perimenopausal Women: A Cross-sectional Study in Western Uttar Pradesh Population. J Midlife Health. 2017; 8: 70-74.

20- Buchanan JR, Santen R, Cauffman S, Cavaliere A, Greer RB, Demers LM. The effect of endogenous estrogen fluctuation on metabolism of 25-hydroxyvitamin D. Calcif Tissue Int. 1986 ;39(3):139-44. 
21- Cass WA, Smith MP, Peters LE. Calcitriol protects against the dopamine- and serotonin-depleting effects of neurotoxic doses of methamphetamine. Ann N Y Acad Sci. 2006 ;1074:261-71.

22- Rossmanith WG, Ruebberdt W. What causes hot flushes? The neuroendocrine origin of vasomotor symptoms in the menopause. Gynecol Endocrinol. 2009 ;25(5):303-14.

23- Holick MF. Vitamin D deficiency. N Engl J Med. 2007; 357:266-81.

24- Bikle D. Nonclassic actions of vitamin D. J Clin Endocrinol Metab. 2009 ;94:26-34

25- Zhao B, Li R, Yang F, Yu F, Xu N, Zhang F, et al. LPSinduced vitamin $\mathrm{D}$ receptor decrease in oral keratinocytes is associated with oral lichen planus. Sci Rep; 2018;8:1-9
26- Varma RB, Valappila NJ, Pai A, Saddu SC, Mathew N. Oral lichen planus: Is vitamin D deficiency a predisposing factor? A case report. IJSS. 2014; 2(7): 230-232.

27- Gupta J, Aggarwal A, Asadullah MD, Khan MH, Agrawal N, Khwaja KJ: Vitamin D in the treatment of oral lichen planus : A pilot clinical study . J Indian Acad Oral Med Radiol 2019;31:222-7

28- Alroy I, Towers TL, Freedman LP. Transcriptional repression of the interleukin-2 gene by vitamin D3: Direct inhibition of NFATp/AP-1 complex formation by a nuclear hormone receptor. Mol Cell Biol 1995;15:5789-99.

29- Yu S, Cantorna MT. The vitamin D receptor is required for iNKT cell development. Proc Natl Acad Sci 2008; 105:5207-12 